\title{
Magnetic Sources of Gold and Freshwater Rivers: Using Ultra-Strong Magnets in the Production of Freshwater and Gold Fishing from Salty and Freshwater Currents
}

\author{
Walid Nabil \\ Department of Geography, Cairo University, Egypt \\ Email: waleednabilalin@yahoo.com
}

How to cite this paper: Nabil, W. (2021). Magnetic Sources of Gold and Freshwater Rivers: Using Ultra-Strong Magnets in the Production of Freshwater and Gold Fishing from Salty and Freshwater Currents. Journal of Geoscience and Environment Protection, 9, 16-34.

https://doi.org/10.4236/gep.2021.912002

Received: October 30, 2021

Accepted: December 6, 2021

Published: December 9, 2021

Copyright $\odot 2021$ by author(s) and Scientific Research Publishing Inc. This work is licensed under the Creative Commons Attribution International License (CC BY 4.0).

http://creativecommons.org/licenses/by/4.0/

\begin{abstract}
The research studies the least expensive ways to produce freshwater from the sea and extract gold, by taking advantage of the characteristics of seawater with a high density compared to the lower density of freshwater, and different estimates of the amount of gold present in seas and oceans (between $10-30$ grams per $1 \mathrm{~km}^{3}$ ) and the total volume of gold in the sea (between $15-45$ thousand tons), which will often be more than that due to the continuous sedimentation from the rivers, and the gold contains impurities that are attracted to the magnet, and therefore it is possible to catch it by means of "super strong magnets"; its strength reaches 1000 tons; it is placed at the bottom of a designated basin, so that the gold is attracted to the bottom, and the most saline types of water are deposited at the bottom, and freshwater floats to the top (by $1 / 4$ ), and this is done by allocating a separate building to the magnet and large areas around it, and designing a water course dedicated to that, and lakes to collect Seawater and pass it on the magnet, which will cause the formation of lakes for freshwater, and other lakes for types of seawater minerals, and it is also possible to use "super-strong magnets" to attract gold from river water and seas, and from the tailings of gold mines, and it will eventually cause Providing huge quantities of freshwater to be used in agricultural and industrial expansion and the establishment of new societies, and gold is gradually turning into a commonly used metal just a "yellow stainless metal".
\end{abstract}

\section{Keywords}

Freshwater Production, Gold Catching, Magnetic Attraction 


\section{What Is the Strategy of This Research?}

This scientific paper is concerned with searching for the least cost-effective ways to extract freshwater from seas and oceans, which results in the extraction of gold ore in large quantities, as well as an attempt to extract gold ore from freshwater and from the remnants of gold mines.

\section{Interaction of Several Ideas and Strategies...What Can You Offer New?}

This research relied on the interaction of several ideas, tools and strategies and their fusion to work together to achieve common goals that complement each other, combining: gold, seawater, properties of freshwater and saltwater, the effect of gravity, water density, and magnetism.

When the researcher was in the study stage at the university at the beginning of the geography department, he knew that the seas and oceans contain the element gold dissolved in water (Mohamed, 1990), and a German mission on board a research ship to extract gold, and that an attempt was made to obtain gold from seawater, but it was unsuccessful, why? For lack of economic viability (Juda, 1995).

The stage of long thinking has begun, And because the researcher knows that: "economic feasibility" has a view that varies from period to period, and profit and loss accounts change from place to place, meaning that there are some projects that have no economic importance because of the high cost of production, which is the real cause for example: The high cost of electrical energy + the high cost of raw materials auxiliary to production, or the cost was high due to the use of expensive machines at the time, or the method itself was less effective, the conditions may change by changing the method and tool of extraction, and conditions change, economic conditions and production tools improve, and energy prices deteriorate and raw materials to assist in production, so that economic feasibility becomes possible, and even turns into a sure opportunity to achieve the highest levels of profitability.

I searched a lot about this research and the details of the subject to no avail, until I found some sufficient details in the encyclopedia "Wikipedia"; as soon as I wrote on the Internet the word: "Gold", and I knew that gold is often found in combination with copper, and as I had previously known that copper contains few elements of iron, so it was noted that using a copper box to place the magnetic compass needle would be It has a slight effect, often limited, on distorting the freedom of movement of the compass indicating precise geographical directions, so it is possible to use the property of the union of gold with impurities capable of being attracted to magnets in the applications of this research.

\section{First: The Volume of Gold in Seawater...Varying Estimates, Difficulty and Expensive Hunting}

The "Wikipedia encyclopedia" on "Gold" says: "Ocean waters contain small 
amounts of gold granules, their concentration in the Atlantic and Pacific oceans is about $10-30 \mathrm{grams} / \mathrm{km}^{3}$, while the waters in the Mediterranean Sea theoretically contain a ratio of 10 grams per $\mathrm{km}^{3}$, Ocean waters contain an amount equivalent to about " 15 thousand tons" of gold, these numbers are three orders of magnitude lower than the numbers found in scientific publications (45 thousand tons) before 1988, which reflects a problem in measuring the small concentrations at that time, or because of the contamination of samples. In the old data, some people have made in the past attempts to recover gold from ocean waters, but these attempts failed, either because of fraud, especially in the early twentieth century, or because of a miscalculation, as happened with "Fritz Haber" who $\mathrm{He}$ conducted research to extract gold from seawater as part of efforts to reduce Germany's debt after World War I, based on data that claimed at the time the presence of gold with concentrations ranging from 2 to 64 parts per billion in seawater, which was theoretically feasible to do the experiment, but after analyzing about 4000 sample of seawater and obtaining concentrations of gold averaging 0.004 parts per billion, it was clear to him that the process was not feasible and the project was stopped" (Wikipedia Encyclopedia, n.d.-a).

\subsection{A Scientific Critique of Estimates of the Volume of Gold in the World's Oceans and Seas}

Here, I would like to record my scientific disagreement with the estimated amount of gold in the waters of the oceans of the planet, which was estimated, as previously mentioned, at about " 15 thousand tons" of gold as a minimum estimate, or even in sources tilted to exaggeration (45 thousand tons) (Wikipedia Encyclopedia, n.d.-a). The reason for my objection is the effects of rivers draining their water into the oceans, and the large loads of different sediments that they receive annually, which in turn contain grains of different sizes of gold, as well as the activity of wave forces and sculpture in the mountains and the erosion of sedimentary and flood beaches, and the role of various human activities, i.e., the ratio, even if it reaches the maximum level of accuracy and impartiality, will continue to be subjected to continuous increase due to riverine, icy, wind and volcanic eruptions. Therefore, we can say that the oceans are the "largest permanent treasury of gold" that continues to be constantly fed and multiplied, with what can be called "renewable stores of gold".

\subsection{Density of Seawater....Saline Water Goes Down...Water Less Salty Goes Up}

According to the applied theories related to density, freshwater is lighter in density than more saline water. Therefore, researchers estimated that the water of the Red Sea (with higher salinity due to high evaporation and the lack of flowing rivers) when it met with the waters of the Mediterranean Sea (less salty compared to the waters of the Red Sea), the waters of the Red Sea made their way down the waters of the Mediterranean (Anwar, 1970). 


\subsection{Is It Possible to Increase the Strength of the "Gravity" to Increase the Difference in the Density of Seawater?}

If we can do this, it is possible that the "degree and strength of the density of seawater" will increase, causing more salty water to accumulate at the bottom, and the freshwater to float on the surface. Using a "super strong magnet" to play this role? And what is the position of gold here?

\subsection{What Is More Expensive, "Gold" or Freshwater, According to the Concept of "Changing Economic Doctrine"?}

At a time of famine and severe drought, freshwater and agricultural crops turn into invaluable wealth, so that the most expensive price is paid in order to obtain a commodity that was highly available before the disaster, so how do we think about changing the method of losing economic accounts to achieve many gains and diverse wealth?

In every scientific experiment or a particular production process, many side effects appear of varying importance, for example: If the goal is to obtain freshwater, which is of insignificant value in a very rainy geographical area, then anything will be produced besides freshwater. It is the highest in economic value, and vice versa as well. If freshwater is a scarce commodity, then the value of gold is the least expensive here.

In any case, we will be interested in several new stages of gold fishing in different ways that have not been used before, knowing that the topic does not need more research and study, but also needs to establish a "college for graduate studies for gold research", and many applied experiments to achieve more gains.

\section{Second: Using a Specific Type of "Super Strong Magnet" and Its Effect on Gold and Seawater}

It will rely on a type of "super-strong magnet" and make some general conceptions of the engineering designs required to create an "artificial magnetic force", to perform the tasks of purifying seawater to extract freshwater, and extract gold atoms, but what kind of magnet do we want?

\subsection{Types of Magnets and Which One Is Better Here? and Why?}

There are two types of magnets that we will think about and rely on, each of them has advantages and disadvantages, scientific needs, requirements for operation and safety means, which are as follows:

\section{- Electromagnet is temporary (only when turned on)}

It generates its magnetic field by passing a uniform electric current through a coil (Or wire). The generated magnetic field disappears when the current is interrupted, and electromagnets are frequently used in electric motors, generators, loudspeakers, magnetic resonance imaging devices, hard disk devices for storing information, heavy cranes and many scientific devices, and the most important 
characteristics are:

Its advantages: Reducing a lot of protection, safety and security measures, ease of transportation, maintenance, and examination of the engineering area and the geographical area surrounding the project.

Disadvantages: The constant need for large amounts of electricity for operation, which greatly increases the cost of the project.

\section{- Semi-permanent self-magnet}

We are talking here about a type consisting of iron, nickel or cobalt with great magnetic capabilities, a type manufactured with strong ferromagnetic materials, The magnetic capabilities are acquired by exposure to a strong magnetic field, to turn into a strong permanent magnet,

There is a group of rare earth elements, most of which are concentrated in the state of China today, where the strongest magnetic material is found by manufacturing a mixed alloy of "Neodymium" + Iron + Boron, which produces "Neodymium" magnets (Wikipedia Encyclopedia, n.d.-b), and there are large sizes of it, and its most important properties As follows:

Its advantages: It is considered the strongest magnet in the world, and this is what this research depends on, Neodymium magnet with a few grams can lift a weight that is a thousand times more than its weight, and it will not need electricity in the process of operation, so the cost of the project is reduced and it does not need energy, Except in the areas of assistance and support for the project.

Disadvantages: It needs great safety measures during the shipping process, and its prices are very high, it requires many means of protection and permanent safety, and the allocation of a fixed space that no one approaches to prevent the magnetic field from a strong step, which causes many diseases, including cancer, for example., that is, requires an independent geographical space in which no living organism exists.

\subsection{The Project Is Based on a "Super Strong" Neodymium Magnet (Weighing Only about One Ton)...With a Lifting Force of Not Less Than 1000 Tons (Not Currently Available or Its Existence Has Not Been Announced Yet) ${ }^{1}$}

It is important to realize the difference in the use of scientific machines leads to completely new discoveries, and opens up horizons that were not in the human mind's perception. This magnet will contribute to doing a lot to make the project successful, but it will cause many risks, threats and problems, which will be minimized as much as possible. Through many engineering designs, preventive measures, and safe uses.

${ }^{1}$ The weight of the "super-strong magnet" is considered unimportant if it reaches between 1 - 5 tons, because the most important thing is its super attractive ability, and it is best to make it in the form of a cube, not more than $1 \mathrm{~m}^{3}$, and it has a flat surface, allowing to provide a large magnetic field of attraction. Valid for conducting various experiments, and it can also be used in genetic modification research on many organisms and plants, for example: It is possible to expose some crops such as wheat or rice to contact with it for a quarter of an hour, for example; it causes a genetic mutation that makes it larger, or more productive, and so on. 


\subsection{Thinking of a "Contingency Plan" for Retirement of "Super-Strong Permanent Magnets" (Execution of the Death Sentence)}

The necessity may call for prior thinking about how to dispense with the "superstrong magnet" for any reason, according to necessity, even at the height of its success and beneficial activity. And the "assassination-quick execution" program was developed at the helm, according to a sequence of a number of procedures arranged and guaranteed results, which vary according to the type of magnet, and start from the use of highly effective explosives, to methods, heating and cooling.

\subsection{Assumed Cost of the Project}

It is the cost of buying a "super-strong magnet weighing about one ton", and its price may reach about 100,000 dollars, in addition to a few engineers and technicians, lifting devices, and equipment of concrete, and an amount of electrical energy that does not exceed the rate of consumption of a house, the cost may reach The closing amount is approximately one million dollars, to be paid only once, while the gains exceed hundreds of millions of dollars in principle, due to the abundant production of freshwater and the validity of its use in agricultural and industrial expansion, population concentration, the production of various salts, and the extraction of gold.

\subsection{What Is the Position of "Gold" with "Ultra Strong Magnets"?}

Gold is characterized by not being subject to magnetic attraction, but rather repels it (Wikipedia Encyclopedia, n.d.-a), but this applies to pure gold, since natural gold contains many impurities, and combines with many metals, including copper atoms, and copper contains impurities of iron, cobalt, or Nickel can be attracted to strong magnets.

But if we consider the presence of "microscopic gold grains" and they are stuck together with impurities of iron, may this iron be subjected to severe rust and lose its ability to attract magnets?! What if there are "microscopic gold particles of high purity without impurities", that is, it will not be attracted to anything, so how is it caught? Therefore, a number of precise engineering designs will be relied upon, which mainly aim to purify seawater, which is associated with catching two types of gold, namely:

- Gold mixed with impurities will be attracted to the magnet: It will be strongly attracted to the magnet to crowd out the saltier water at the bottom.

- Pure gold incompatible with the magnet: It will move away strongly from the magnet, crowding out and mixing with the less salty (fresh) water above.

\subsection{What Is Expected about the Shape of Gold and Its Composition?}

It is expected that gold will be characterized by containing various impurities, and it can be called "sponge gold". It takes place in the case of melting, which eventually results in the appearance of a "sponge gold ingot", meaning that the weight of a cube of gold caught by the magnetism will be lighter than the same 
volume of a cube of molten gold.

\subsection{Where Will the Gold Be Concentrated?}

The gold will be concentrated in the following places:

1) "Freshwater filters": to seize microscopic gold particles from freshwater, which repelled by the action of the magnet exceeded the force, and this gold is considered the purest in terms of the lack of impurities, because if it contained iron impurities, it would have been attracted to the magnet and stuck to the bottom of the magnetic attraction basin, and some The impurities here, although rare, are difficult to purify and separate from the gold.

2) "Ultra-Saline Water Filters": To sequester microscopic gold particles from the highly saline water, which are attracted by the force of the magnet exceeds the force, due to the fact that this type of gold contains iron derivatives, and of course this gold contains some iron impurities, but it is easier to purify Gold later by smelting or extreme centrifugation.

3) The bottom of the seawater separation basin: It will be concentrated at the bottom due to the strong magnetic force.

4) The ceiling of the seawater treatment basin: The pure gold granules will be concentrated in the ceiling of the basin due to the repulsion with the magnet.

\subsection{When Are Filters Changed? and Collect Gold from the Bottom and Roof of the Magnetic Basin?}

We are supposed to say that the process of changing the filters and collecting the gold should be based on the amount of water passing through it. The filter is supposed to be changed after purifying 1 cubic kilometer, (which contains between 10 - 30 grams of gold ore) but it is easier. The filter is replaced approximately once every day, and this is done in the separating filter tubes between the water collection basins after magnetic attraction. Places far enough away from the power and dangers of the magnet have been chosen, to facilitate the process of changing and changing.

The gold concentrated at the bottom and ceiling of the "seawater passage basin for magnetic examination": It is expected that the great gravity of the magnet will prevent the gold atoms from moving in the water current, as it will not enter the "filters", so it is better to put a thick and delicate cloth, while It resembles a "carpet" of a different color than the color of gold and the color of the basin, so that the color of the carpet is "white", for example, and then the carpet is changed after examining every 1 cubic kilometer of seawater, and this will only be done by removing the magnet as much as possible, and after This is done by burning the carpet and extracting the gold in the usual ways, including, for example: By combining with wolfberry.

\subsection{How Will Gold Be Extracted from the Filters and the Carpet?}

By melting the filter itself, if the filter is a flammable substance, the issue requires burning it, or chemically analyzing it. 


\subsection{How Much Gold is Expected to Catch in the End?...The Profitable Amount of Gold Requires Refining an Amount of Water Equivalent to a Large River}

According to the average volume of gold, which seemed to be estimated at between 10 - 30 per square kilometer of seawater, (which is equal to 1 billion cubic meters, seawater), and the greater the greed in refining larger quantities of water; The amount of gold increased, and if greed increased, the process of refining seawater would cause the generation of very large quantities of freshwater equivalent to the size of a "big river" in every sense of the word, sufficient for entire countries with an average population of at least 100 million people!

The economically profitable real quantity in the production of gold from the sea should not be less than 50 - 100 grams per day, and as it was mentioned that the cubic kilo contains an average of approximately 10 grams; This means refining between 5 - 10 cubic kilometers per day, and if we assume that the amount of freshwater production will reach $1 / 4$ of the seawater, then every 10 kilos of seawater will allow the production of 2.5 cubic kilometers of freshwater, which is a very large amount Equivalent to the volume of river discharge of the largest rivers in the world.

\subsection{The Gold Extracted from the Sea Is Still Very Little and Does Not Change Much of the Gold Market in the World}

Production of the main mines that are most productive in the world, but it gives an alternative way of production and avoids monopoly, and opens great prospects for modifying the tools and methods of seawater refining places directly with Reducing security measures to save costs and increase profit.

\section{Third: Precise Engineering Designs for the Success of the Role of "Super-Strong Magnets" in Producing Freshwater from Seawater and Fishing for Gold}

A number of procedures, engineering designs and prefabrications will be followed, which are appropriate to the "functional role of the super strong magnet", as follows:

- Choosing a geographical area with stable characteristics and coherent sedimentary soil: It is very important to choose a geologically stable area, which is known for its scarcity of exposure to earthquakes and volcanoes, and that its geological formations are due to "sedimentary rocks" why, to reduce any concentration of iron metal or its derivatives or other minerals that are often mixed with it in the form of simple impurities, so that it is affected by magnetic attraction, and the chances of soil erupting due to the less presence of iron particles strongly attracted to the magnet, and thank God that many areas overlooking the seas and oceans of the world there is "sedimentary soil" in it, because the waves carved the mountainous areas, broke the debris, moved it, removed it and scattered it, and dug in it due to the decrease in the level of the oceans during the ice ages, until the sedimentary layers varied, and the thickness of some of them reached about 100 meters below the sea- 
water, despite this, samples must be taken by drilling deep wells exceeding 50 meters at least, and the sample confirms the scarcity of iron.

- Choosing an elevated coastal area overlooking the sea, far from pollution with a steady sea current: (See Figure 1), to provide a safe environment for the work of the ultra-strong magnet, and to keep fishermen and fish away, as well as to take advantage of the sea current to replenish the water, and drain the highly saline water into the sea. And exposing it to erosion and scattering away from the coast, to reduce the distortion of water characteristics, salinity, temperature and others.

- Choosing a mountain or building wide heights of not less than 100 meters above sea level: And equipping it with tunnels and precise paths similar to "the catacombs of the Great Pyramid in Egypt" (see Figures 2-4), related to the presence and movement of the super strong magnet, to avoid Infection of project workers or visitors with cancer diseases and for conducting various maintenance and examination operations. The heights will provide the function of pumping freshwater forcefully to the various residential and agricultural areas surrounding the station. It will also allow great freedom in the passage of seawater in the stages of magnetic purification and various basins to complete the desalination process of seawater.

- Processing of a quiet marine water stream over heights of the "Mount Magnet": no more speed for half a meter per second, so that water granules can

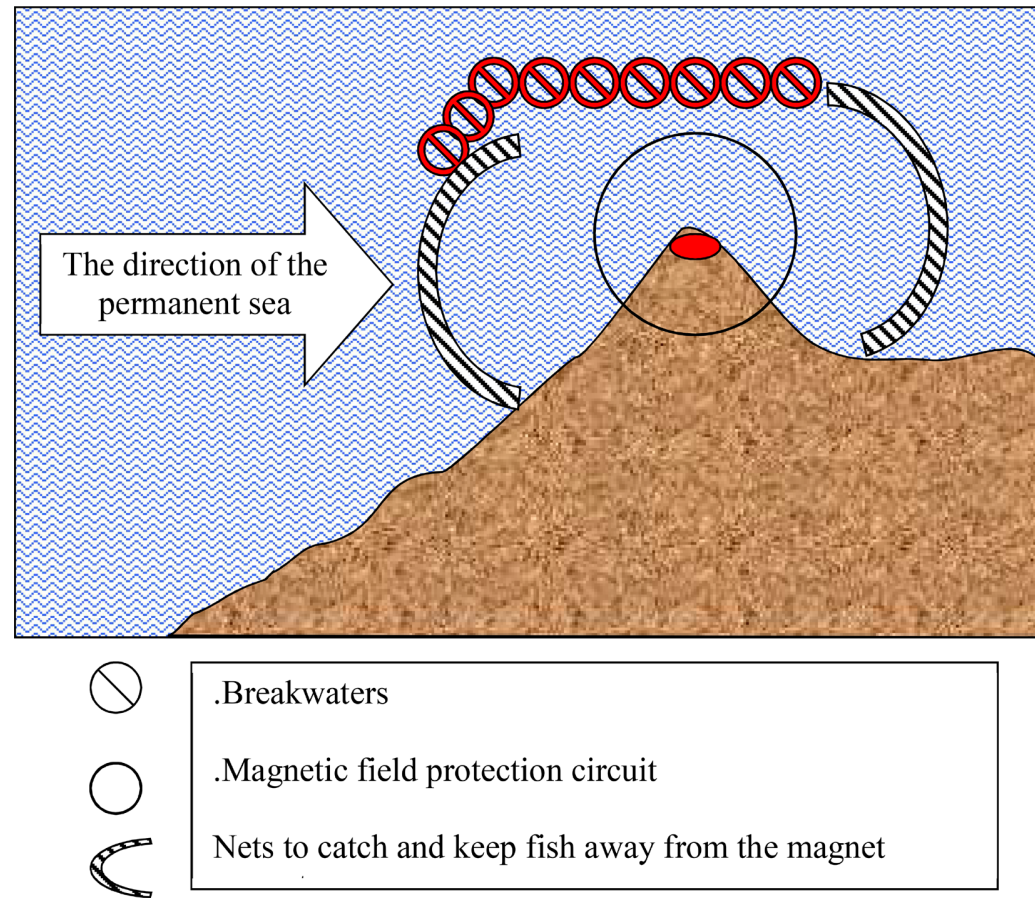

Source: Prepared and designed by the researcher.

Figure 1. A hypothetical site for a high coastal area overlooking the sea, far from human activity and the main and marginal population concentrations, in front of it with breakwaters to provide maximum protection from sculpting waves, and to keep fishermen away from the magnetic field. 


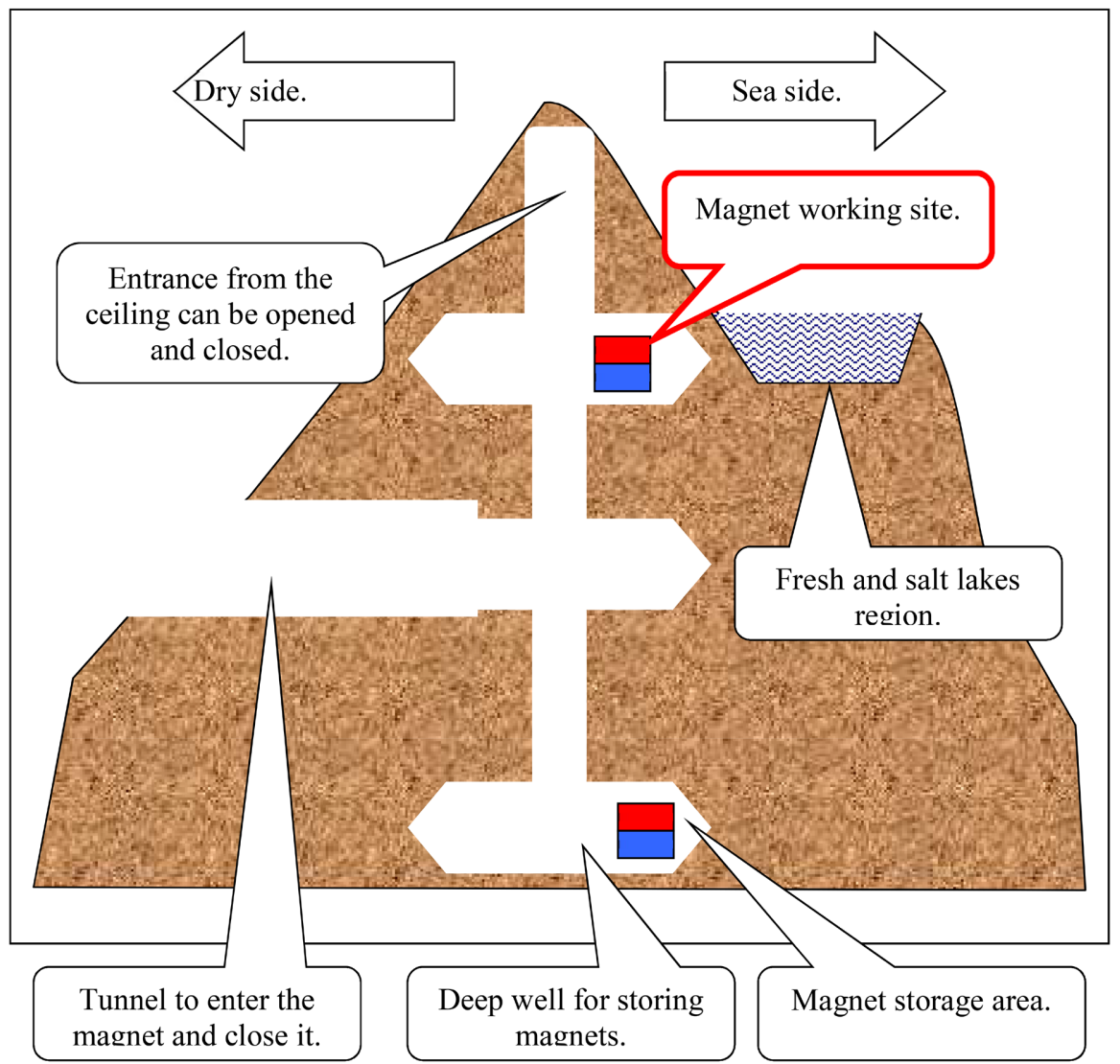

Source: Prepared and designed by the researcher.

Figure 2. A cross section of the general engineering design shows the "super strong magnet mountain" and its system of presence and movement in what resembles the "basement of the Great Pyramid in Egypt", which is a shield and tunnels that do not contain iron that allow the magnets to be removed for a safe distance (in destinations or stations at a distance between 100, 200, 300 meters, and more) to avoid infecting workers or visitors with cancer, and to perform various maintenance and examination operations.

be rearranged according to its intensity. The current and quantity of water through the day, to see the capacity of "super-force magnet" to refine seawater, as a simple calculation, for example: 1 day $=86,400$ seconds that on the day can be crossing (half $86,400=43,200$ per day), if many ultra-power magnets are used to increase seawater purification and gold; The amount of water passersby will be infused, increasing daily production of freshwater, and gold.

- Put ultra-bottom magnet: It is best to make nature works with us and in our class, so it is best to put super power at the bottom of the water.

- Create a "hunting channel and magnetic examination": Special design is required, similar to "path of the snake" (Strenuous) and make some future adjustments to increase their effectiveness.

- Shape and characteristics of "Hunting Channel and Magnetic Inspection": It is important to create an independent channel entrance and independent director, "is subject to full control from afar (see Figure 5, Figure 6), and installed with water closure or slot according to necessity. 


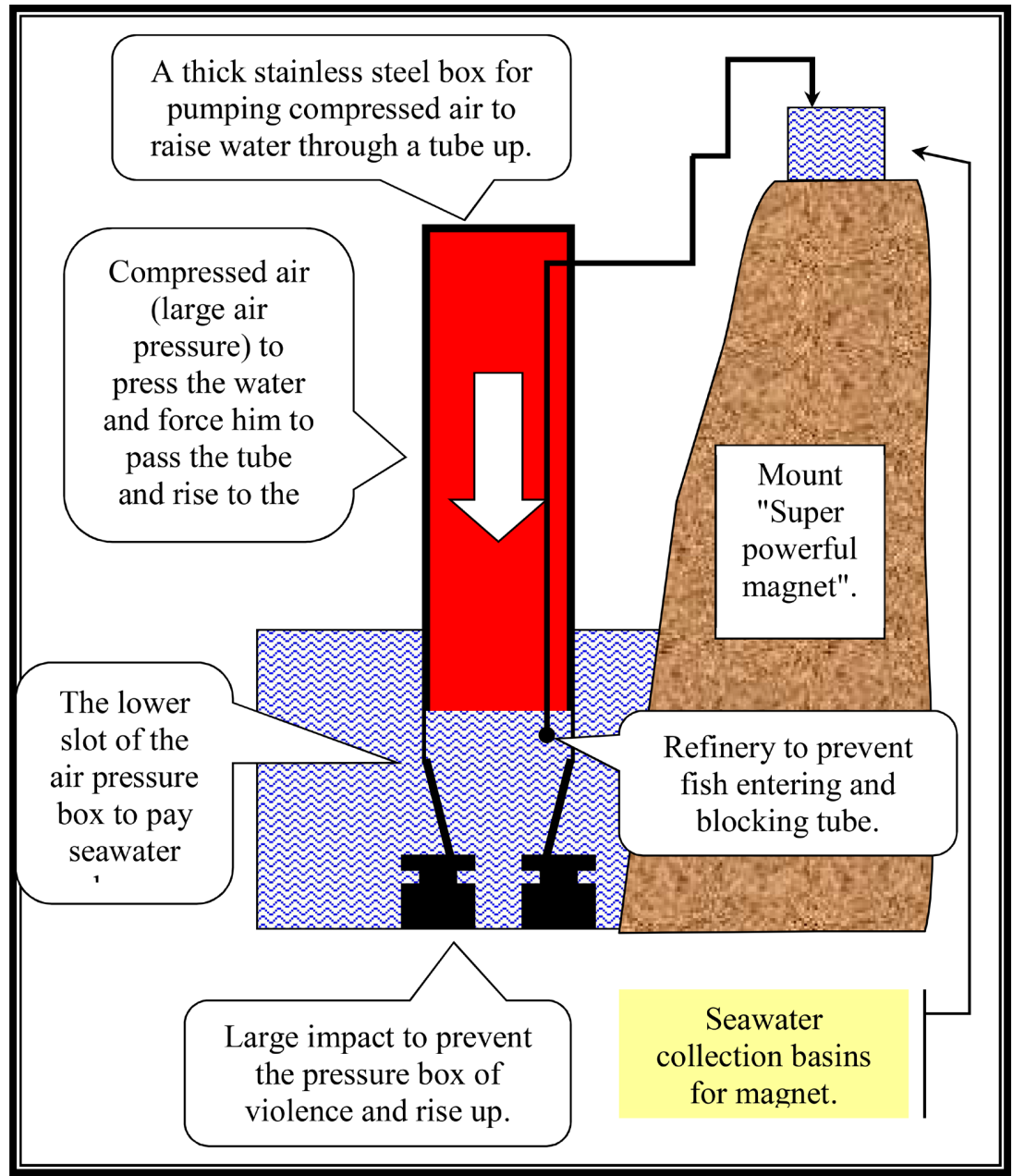

Source: Preparation and design of the researcher.

Figure 3. Easy and inexpensive way to raise seawater across pipes to top by creating a thick stainless steel box and is firmly installed at seabed and pumping the amount of compressed air to force seawater on traffic in the easiest ways in the tubes ending with basins Collecting seawater on the mountain of the magnet is super-strength, and tens of this fund can be established to raise more water over the mountain.

- Create a trench in the middle of the channel is located down the trend to pass water from above a top bridge: which will be placed in it is super powerful magnet, but why? Perhaps to make this magnet work with electric current, and may require necessity to change the magnet and switch in a stronger magnet, or may be changed where the water current is changed for natural causes, (The constructs and motion by sculpture and deposition, drought, flood...), or for human reasons (such as dispensing for the lack of having or sight of its location, etc.).

- Creating a cave or a strong ceiling of material does not hinder the work of the magnet or cause the collapse of its magnet: Here we will exclude concrete with ferrous water, and maybe make some quick and easy tests to check for a simple resistance to the work of magnet, often will succeed Private white marble. The stone blocks are without iron and metal impurities. 


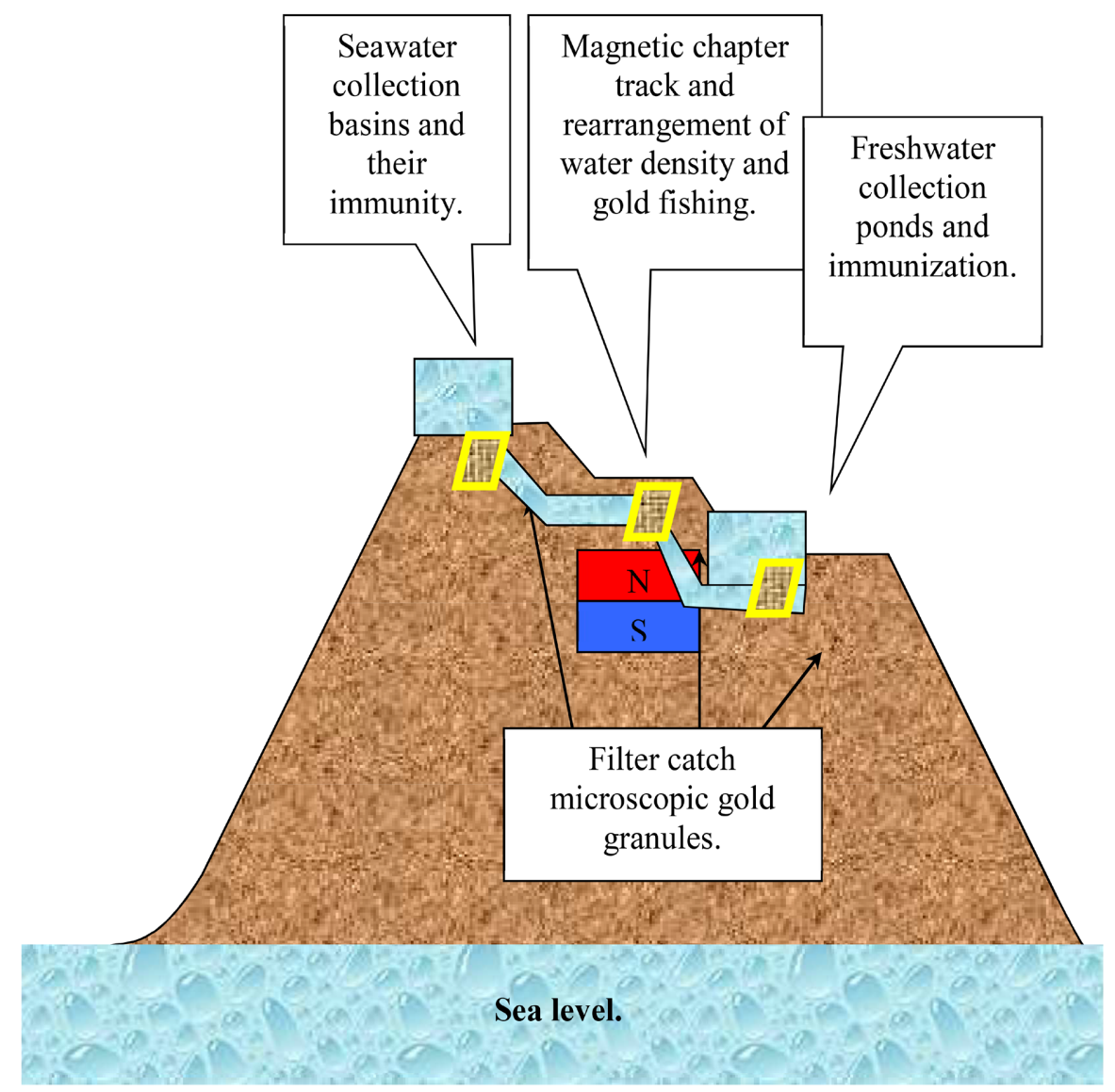

Source: Preparation and design of the researcher.

Figure 4. picture of the view of the "Mountain Magnetic Separation System" as it seems from the sea, high levels of crude seawater collection (salt) and the location of super-force magnet and its activity in the separation of freshwater and sedimentation and freshwater storage.

- Processing an independent tube per 10 centimeters in the magnetic check basin if the water depth above the magnet 1 meter: I will leave 10 centimeters at the bottom to start putting pipes every 10 centimeters, and anyway the first tube that will follow the bottom directly will be dedicated to disburse Water Slate (see Figure 5), Panama will allocate the top tube "at the top" at the surface to collect the water closest to the ice, while other pipes will be the combination of different salinity, which contain specific elements of the concentrations of some special salts.

- Create several lakes after water on the super-force magnet: It is dedicated to drainage of different pipes, and must pass after falling from what is like a "small waterfall" (enough falling from almost 10 meters) to get rid of harmful magnetic influence waterproof, Lakes are:

1) Lake waterproof closest to freshity: The proportion of salinity is likely to be less accepted for drinking, and may require the need to be subject to restricting super-force magnets again to increase their purity.

2) Lake for high salinity water: It is surprised to turn into a "large saline" to 


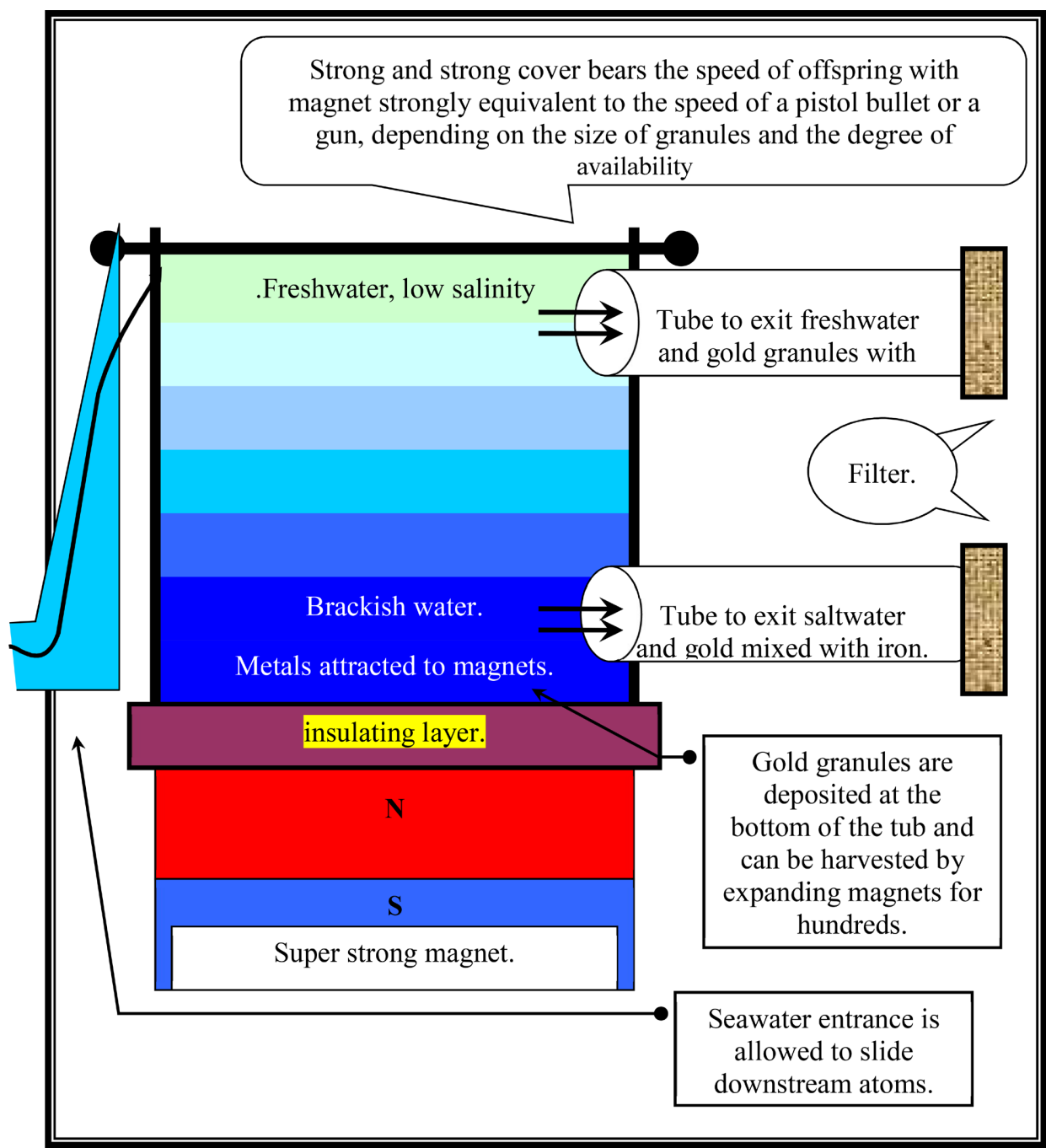

Source: Prepared and designed by the researcher.

Figure 5. A side section of the way the super strong magnetic attraction works and rearranging the density of seawater. And down in the northern hemisphere $(\mathrm{N})$, and the north pole to the south and up in the southern hemisphere (S), to enhance the strength of magnetic attraction and not oppose nature, or distort the magnetic field of the region.

leave to dry the sun to turn salt.

3) Specialized lakes for therapeutic tourism (specialized salts): To take advantage of the presence of certain qualities of salts, such as Potassium, Magnesium and others.

\subsection{Magnetic Tubes}

It is possible to create a "long tube consisting of plates of supermagnetic attraction" to rearrange the density of the water, so that the heavier density (the most salty water) sticks to the wall of the tube, while the lighter in density (the least salty water) moves away from the wall, to be concentrated in the middle, Waiting for it here is another tube consisting of a material that is not affected by magnetic attraction (for example, plastic or glass) and the semi-freshwater enters 


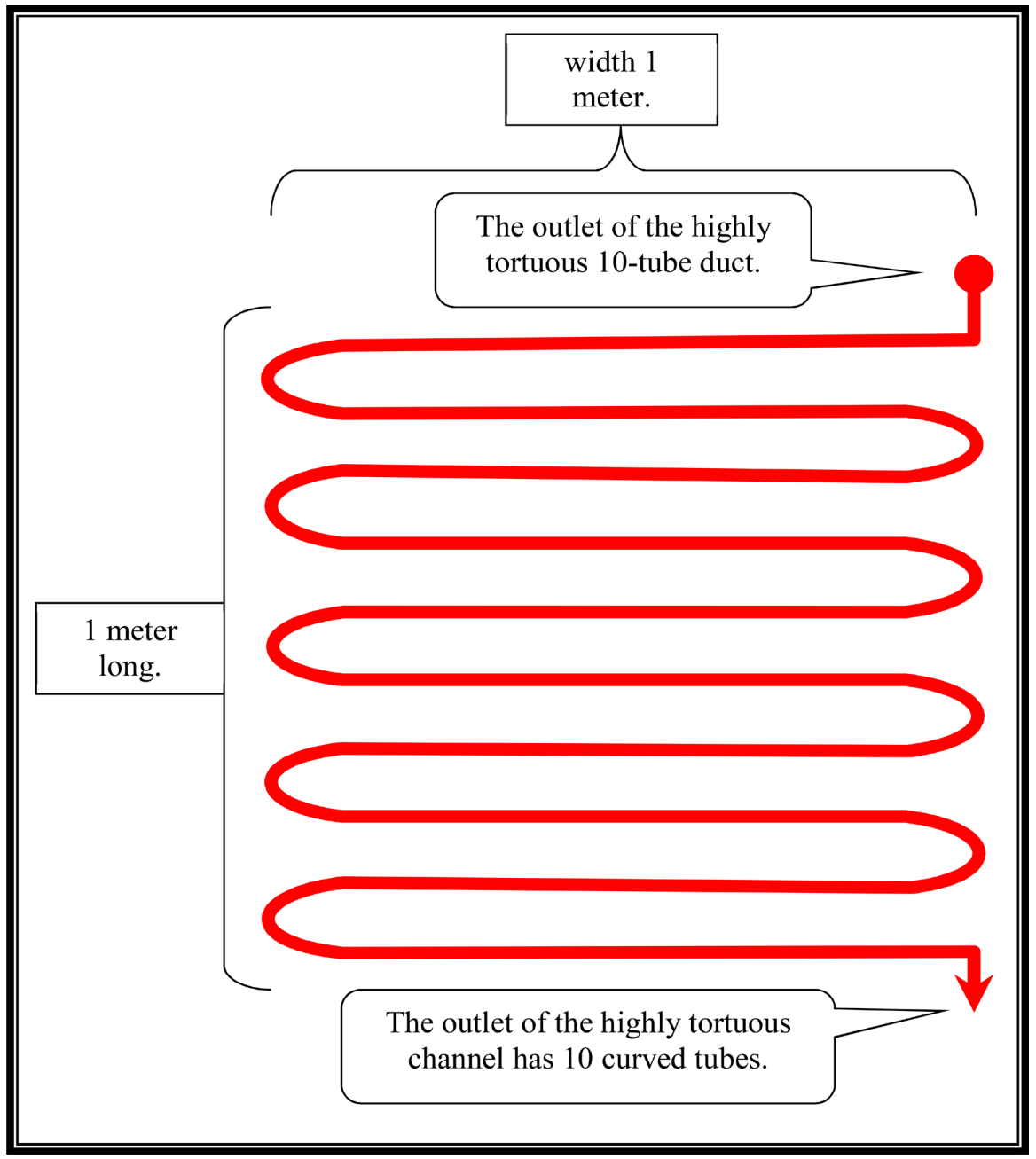

Source: Prepared and designed by the researcher.

Figure 6. The path of the "highly zigzag snake channel" (10 zigzag tubes) passing over the "super-strong magnet" at a speed of 1/2 meter per second. Water grains according to density, freshwater floats up in addition to microscopic gold particles, and very saline water to the bottom in addition to microscopic gold grains mixed with iron atoms.

an independent path (see Figure 7).

\subsection{The Use of a Special Engineering Design to Catch the Most Crumbly Gold in Gold Mines}

The successful process of catching gold from seawater will contribute to thinking about taking advantage of the "water used to wash gold crumbs" and doubling the annual production of gold for the same mine, or to say doubling the production of gold in all mines of the world, but what makes this water contain large quantities of gold equal to the same amount extracted from the large gold granules? Because water is a tool for mechanical sculpting, and because there are some golden granules that did not succeed in merging, agglomerating and crystallizing in solid, prominent pieces, and therefore assuming the presence of gold in the same soil is actually a high possibility (see the details of Figure 8). 


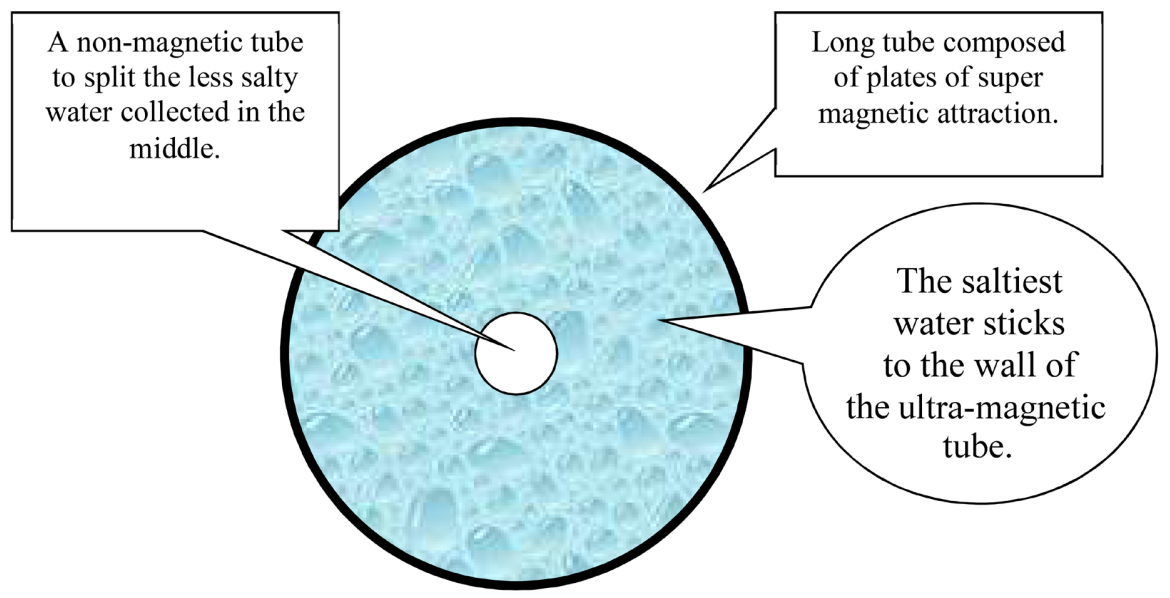

Source: Prepared and designed by the researcher.

Figure 7. The working method of "a long tube consisting of plates of super magnetic attraction" and concentrates the most salty water on the wall of the tube, while the less salty water collects in the middle to travel in a tube specially equipped for it.

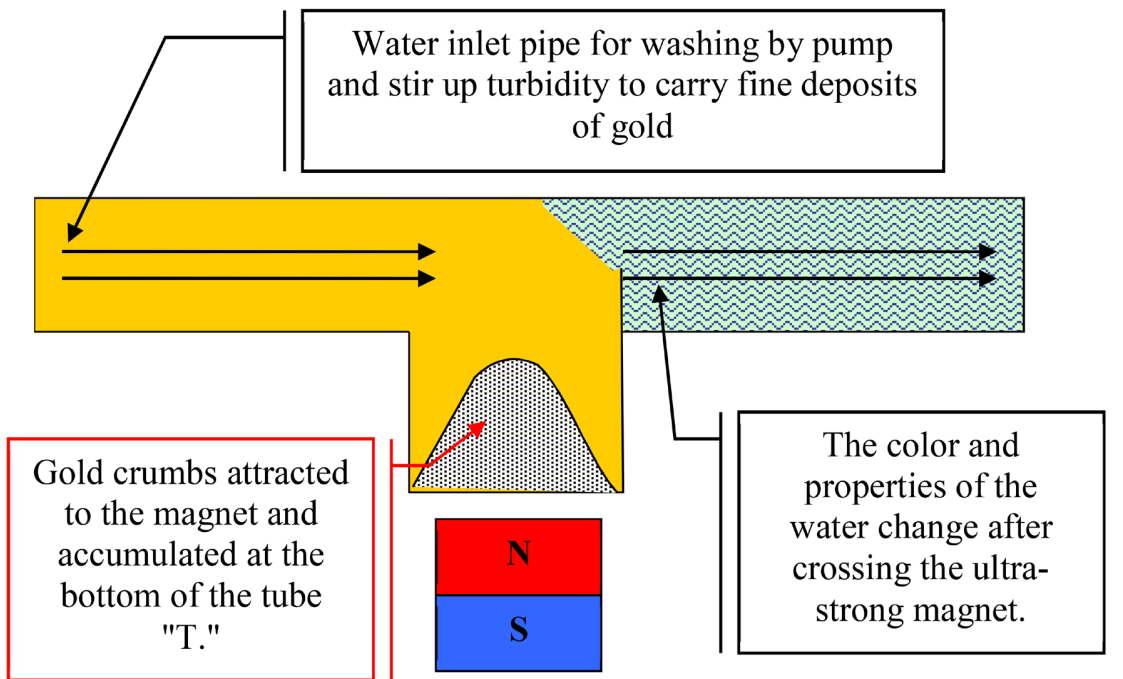

Source: Prepared and designed by the researcher.

Figure 8. "T" basin for the process of fishing for gold from the water used to wash the gold crumbs, which is done by pumping the water used after washing and stirring the dust and crumbs that are in it to pass on the "super-strong magnet" to precipitate some gold granules at the bottom of the basin.

\subsection{Are Bacteria, Plankton and Micro-Organisms Likely to Be Affected by Magnetic Attraction? Is This Good or Bad?}

We must first search for the presence of iron in the bodies of bacteria and microscopic organisms found in seas and oceans, and will magnetic attraction affect them negatively or positively? We believe that this is a very big topic that many scientists will be interested in the future, but from the initial scientific perception appears. The magnetic attraction can cause the killing of many bacteria and microorganisms.

It is expected that bacteria and viruses will be subjected to distortion in shape, 
motor behavior and functional role, so they will appear under the microscope differently than they were before exposure to the super magnetic attraction, and they will move in a way similar to the reeling caused by drug abuse! We believe that it "will go through a new stage of dangerous genetic evolution" and "a complete change in the functional role of each of them", for example: The role and activity of "Decomposition bacteria" will change to another activity, and so on.

\section{Fourth: The High-Power Mobile Magnet Used in Gold Hunting}

Some strange methods used against gold will be referred to in strange and previously unknown ways, and this is because of greed and the constant desire of human beings to obtain wealth in any way.

\section{Is It Possible to Drag, Float and Drag a "Super Magnet" Across an Ordinary Ship?...Crazy Ideas Will Never End}

Achieving success encourages the path to success. It is possible to drag the super-strong magnet by pulling it with ropes after attaching the buoys on it, and navigation with it across oceans, seas, and rivers as well, in tracks far from the potential paths of ships, to lead to the greatest attraction of gold atoms related to atoms Iron, which is one of the crazy ideas for hunting gold (see Figure 9).

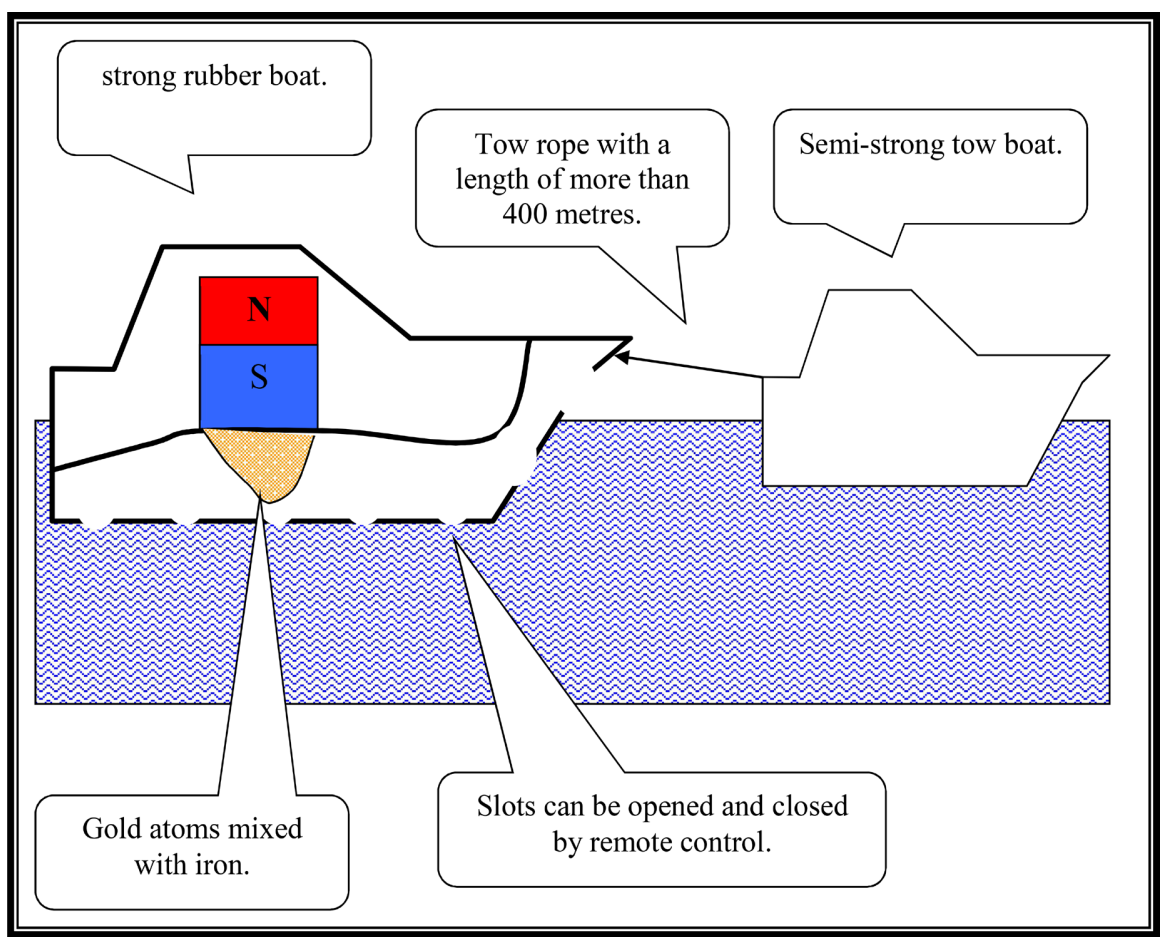

Source: Prepared and designed by the researcher.

Figure 9. One of the crazy possible attempts to drag the "super magnet", float it and pull it through an ordinary ocean gold-fishing ship in deep water areas far from the main ships' tracks. 


\section{Fifth: Effects and Results on (The Collapse of the Gold Market and Economic Status-The Excessive Abundance of Freshwater-Human Disorder)}

The multiplicity and diversity of results is the result of the occurrence of something important and highly influential in human societies, and this does not mean that only the economy will change, but the entire lifestyle will be completely overturned.

\subsection{Gold Fever What Can you Do?...How Do Crazy People Think?...Will You Receive Freshwater in the Desert and the Sea?...Will Geography Change?}

After the success of the initial experiments with great economic returns, informal entities and illegal organizations run by criminal groups will arise in what looks like "warlords", and "armed gangs" to fish for gold from seawater, and it is expected that scientists will be active to find many newer tools and better alternatives to catch more gold and speed up its pace, and there will be many problems, quarrels and acts of violence between the workers in the "freshwater and gold fishing stations", and even many criminal practices and foolish acts will occur.

\subsection{Get Rid of Freshwater!}

Perhaps it is sufficient to catch gold only from seawater, with the disposal of freshwater by deliberately leaving it to fall into the sea!; To create some "fresh bays" in the seas and oceans, and the subsequent impacts on marine organisms and the movement of water currents, and the resulting difference in evaporation rates and their effects on the global climate, especially coastal areas, and the failure to take precautionary measures to protect the environment and preserve different organisms, as well as protecting workers from Magnetic damage!

\subsection{Artificial Swamps for Freshwater}

The random pumping of freshwater into the plains will result in the formation of large swamps, which will turn into a gradually swollen and stagnant lake, and an area infested with diseases, and desert areas will turn into permanent swamps, and the consequent fluctuating effects of the natural environment, distributions of atmospheric pressure areas on the surface of the earth, and what leads to disturbances unpredictable weather.

\subsection{The Inflated Production of Gold by Fishing from Seawater and River Water}

If it is possible to catch all the estimated gold in the waters of the seas and oceans on the surface of the earth; Let us rely here on a maximum estimate of 45 thousand tons, but even if we assume that it is between 50 - 100 thousand tons, the amount is still close to the annual copper production currently., but this technique will contribute to fishing for gold from river waters; It is the highest in 
terms of the average amount and percentage of gold it contains per cubic kilometer. Therefore, the production of water-gold will swell in the world.

\subsection{The End of "The Lead of Gold" and Its Transformation into a "Shiny Yellow Metal" Is Less Valuable Than Now}

When the first strong success of gold mining and extracting it in an economically profitable way from the waters of the seas and oceans is announced, the "global gold market" will collapse and the value of gold will drop to $1 / 4$ suddenly, far from being affected by the rule and principle of "supply and demand", then gold will decline to $10 \%$ From its current value, gold turns into a non-precious metal, slightly higher than copper, and becomes available for use by everyone at a low price, and pervasive in all areas of life, as a metal whose importance lies in not being exposed to rust, in a position similar to "stainless steel", to make of gold food utensils and all Kitchen utensils, medical devices, door handles, anything that replaces aluminum, traps, traps, and retires, from aluminum foil, to consumer packaging for food, beverages, and medicine, electrical wires, boats, and many different kinds of ships, and parts There are so many of all means of transportation, walls, floors, and facades of houses, and it is very rare that gold does not enter any field of human civilization.

\subsection{Wars to Retain the Primacy of Gold...Enemies Ally Themselves with Each Other Honestly and Faithfully in Defense of the High Value of the Gold Stock}

The war will break out just by thinking and real striving to produce gold in an easy way, because the "economic doctrine" about wealth throughout history has been centered on hoarding gold, and the world's banks have allocated gold bars as a safe cash cover, so the stage of comprehensive use of gold will not come before it passes first In the "phase of blood" and the deaths, threats, vulgarities, bargains, deals and conspiracies, an "unclean war", the believer will ally with the unbeliever, the poor with the rich, and the enemy will believe and be saved with his enemy, to preserve the value of their stock of gold, before it becomes possible to "catch gold from seawater" for all human societies.

\subsection{What after the Collapse of Gold and Its Transformation into a Mere "Yellow Metal That Does Not Rust"?}

When the king dies, this means that a new king will ascend the throne, meaning that when gold falls from the top of the economic leadership, it will allow minerals or other things to rise in status and increase their economic value, and people are divided between those who love excessive spending, and others who fall into excessive saving of wealth.

\subsection{Pure Water...What Is the Future of Water Use? Air Is a Freshwater Source}

It is estimated that the future of the use of freshwater will also differ. There are 
one or two stages of development that humanity is waiting for, or seeking, and then the rivers will not have an actual value as a store of freshwater, which are:

1) The first future phase: "Implanting machines and electronic devices to collect water from the air".

2) The second most advanced future stage: "Genetic modification granted to the human, animal and plant body by collecting water from the air to quench thirst in a natural way".

\section{Conclusion}

How and why did the "Geographical Detection" movement begin? Man does not walk before his thoughts and needs to move him before his muscles. The ideas, theories, estimates and initial perceptions about the different geographical areas are what encouraged adventurers and explorers to verify them, prove them or disagree with them. We still need a lot of "virtual scientific theories" to encourage applied attempts. To make sure of their validity, human and science progress together.

The success of any project, idea, or even an experiment means more activations to move in the same direction, and achieve more successes and even excellence in this field, not hunting for gold in a new condition, and the most valuable thing that humans have will remain innovation, renewal and creativity, and the most valuable thing they save is an act. Goodness, wealth and money are hidden with God.

\section{Conflicts of Interest}

The author declares no conflicts of interest regarding the publication of this paper.

\section{References}

Anwar, A. A. (1970). Navigation and Marine Sciences among the Arabs. The World of Knowledge, Vol. 13.

Mohamed, A. T. A. (1990). Geography of the Seas and Oceans. University Knowledge House.

Juda, J. H. (1995). Geography of the Seas and Oceans. Manshet Al-Maaref.

Wikipedia Encyclopedia (n.d.-a). Gold. https://en.wikipedia.org/wiki/Gold

Wikipedia Encyclopedia (n.d.-b). Neodymium. https://en.wikipedia.org/wiki/Neodymium 